\title{
Human papillomavirus prevalence and type distribution among women attending routine gynecological examinations in Saudi Arabia
}

Abdulaziz AlObaid ${ }^{1}$, Ismail A Al-Badawi ${ }^{2^{*}}$, Hanan Al-Kadri ${ }^{3}$, Kusuma Gopala ${ }^{4}$, Walid Kandeil ${ }^{5}$, Wim Quint ${ }^{6}$, Murad Al-Aker ${ }^{2,7}$ and Rodrigo DeAntonio ${ }^{5}$

\begin{abstract}
Background: Cervical cancer (CC) is caused by persistent infection with high-risk (HR) human papillomavirus (HPV) types. In Saudi Arabia which has a population of 6.5 million women over the age of 15 years, approximately 152 new cases of CC are diagnosed and 55 women die from the disease annually. Nevertheless current epidemiological data for HPV in this population are limited. This study evaluated the prevalence and type distribution of HPV and documented the awareness of HPV infection and health-related behavior among Saudi and non-Saudi women attending routine examination.

Methods: This was an observational, epidemiological cross-sectional study conducted between April 2010 and December 2011 at three hospitals in Saudi Arabia. Cervical samples from women aged $\geq 15$ years, who were attending routine gynecological examinations were collected and tested for HPV-DNA by polymerase chain reaction and typed using the SPF 10 DEIA/LiPA25 system. Two questionnaires on health-related behavior and awareness of HPV infection were completed.
\end{abstract}

Results: A total of 417 women, mean age (standard deviation) 41.9 ( \pm 10.4$)$ years, were included in the final analysis, of whom 77\% (321/417) were Saudi nationals. HPV-DNA was detected in 9.8\% women (41/417, 95\% confidence interval [CI]: 7.1-13.1). The prevalence of any HR-HPV by age was: $25-34$ years: $3.0 \%$; $35-44$ years: $4.5 \% ; 45-54$ years: $3.2 \%$; $>55$ years: 10.9\%. The most prevalent HR-HPV-types were: HPV-68/73 (5 cases); HPV-18 (4 cases); HPV-16 (3 cases). The most prevalent low risk (LR) types were HPV-6 (4 cases); HPV-42, HPV-53 and HPV-54 (2 cases each). The prevalence of HPV was higher among non-Saudi nationals vs. Saudi nationals $(16.7 \%$ vs. $7.8 \%, P=0.0234)$. No statistically significant risk factors were identified: $32.2 \%$ (101/314) women were aware of HPV and 89.9\% (285/317) showed an interest in HPV vaccination.

Conclusion: The overall prevalence of HPV was 9.8\% in Saudi Arabia, but was higher in women over 55 years, as well as in non-Saudi nationals. These data provide a reference for public health authorities and may also help in determining future policies for the prevention of CC.

Clinical trial registration: NCT01213459

Keywords: Human papillomavirus, Saudi Arabia, Epidemiology

\footnotetext{
*Correspondence: i_albadawi@yahoo.com

${ }^{2}$ King Faisal Specialist Hospital \& Research Centre, P.O. Box 3354, Riyadh

11211, MBC-52, Saudi Arabia

Full list of author information is available at the end of the article
} 


\section{Background}

Cervical cancer (CC) is the third most frequent cancer in women throughout the world and was associated with an estimated 530,000 new cases and 275,000 deaths in 2008 [1]. The global age standardized incidence rate for CC is 15.2 per 100,000 population [2]. Saudi Arabia has a population of 6.5 million women over the age of 15 years [3]. Based on the available data, around 152 women are diagnosed with $\mathrm{CC}$ and 55 die from the disease annually, corresponding to the $11^{\text {th }}$ most frequent cancer among women of all ages in this population [3]. However, as not all CC cases are reported in Saudi Arabia, there is a concern that the real incidence of CC may be somewhat higher.

It is known that CC is caused by persistent infection with high-risk (HR) human papillomavirus (HPV) types [4,5], of which HPV-16 and HPV-18 are responsible for approximately $70 \%$ of the overall cases [6]. Two HPV vaccines are currently licensed in many countries: a bivalent vaccine (Cervarix ${ }^{\circ}$, GlaxoSmithKline, Belgium) and a quadrivalent vaccine (Gardasil, , Merck and Co., Inc., Whitehouse Station, New Jersey), both of which are well-tolerated and have good efficacy profiles [7-14]. The introduction of these vaccines provides an opportunity to reduce $\mathrm{CC}$, but the introduction of such a preventive measure, requires baseline data on national epidemiology and prevalent circulating HPV strains.

The epidemiology of HPV amongst women in Saudi Arabia is not fully understood and only limited publications about the prevalence, detection and genotyping of HPV [15-17] and attitudes towards screening are available in this population $[18,19]$. In order to bridge this gap and provide baseline data, this study was undertaken to evaluate the prevalence and type distribution of HPV, including HR and low risk (LR)-types, among Saudi and non-Saudi women. The study also documented the level of awareness of HPV infection, health-related behavior, and potential risk factors for HPV infection among women attending routine gynecological screening.

\section{Methods}

\section{Study design and study population}

This multicenter, observational, cross-sectional, epidemiological study (NCT01213459) was conducted between April 2010 and December 2011 at three large hospitals: King Fahd Medical City (KFMC), King Faisal Specialist Hospital and Research Centre (KFSH and RC) and King Abdulaziz Medical City-National Guard Health Affairs (KAMC-NGHA) in Riyadh, Saudi Arabia. Women aged $\geq 15$ years undergoing routine gynecological examination and willing to provide a cervical sample were enrolled. Pregnant women above 25 years or women with a known diagnosis of immunosuppression, or those who had undergone hysterectomy were excluded from the study.
Cytological examination of the collected cervical samples was undertaken locally in the laboratories at each hospital. The investigator issued two questionnaires for completion by all women; these assessed health-related behavior and their awareness of HPV. The responses to these questionnaires were anonymous and confidentiality was maintained.

\section{Sample collection and laboratory procedures}

Endocervical samples were also collected during the first visit by a trained practitioner/gynecologist using a cytobrush and placed in a liquid-based cytology transport medium (PreservCyt ${ }^{\circ}$, ThinPrep Pap Test; Cytyc Corporation, Boxborough, Massachusetts). Samples were stored at room temperature at the sites for four weeks and then at $-20^{\circ} \mathrm{C}$ until shipment to the DDL Diagnostic Laboratory (Rijswijk, The Netherlands).

DNA was isolated from $500 \mu \mathrm{l}$ of the cervix-vagina on a MagNA Pure Robot (Roche Diagnostics, Almere, The Netherlands) using the MagNA Pure LC Total NAILV kit and eluted in $50 \mu \mathrm{l}$ of elution buffer [20]. Samples were tested for HPV-DNA at DDL by broad-spectrum polymerase chain reaction (PCR) using HPV short PCR fragment 10 (SPF-10) and PCR DNA enzyme immunoassay (PCR-DEIA) to amplify and recognize at least 57 HPV genotypes by hybridization with a cocktail of nine conservative probes. If positive by SPF10-DEIA the amplimers were further analyzed by Line probe assay 25 (LiPA25) version 1 system (Labo Biomedical Products, Rijswijk, The Netherlands). This Line probe assay 25 (LiPA25) version 1 system (Labo Biomedical Products, Rijswijk, The Netherlands) was used to genotype $25 \mathrm{HR}$ and LR HPV types [21]. (The sequence variation within the $\mathrm{SPF}_{10}$ inter-primer region did not allow HPV type 68 and 73 to be distinguished $[22,23])$. DEIA positive-LiPA negative samples were denoted as non-typeable.

\section{Sample size calculation}

The primary objective of the study was to describe the prevalence and types of HPV (including multiple infections) among women $\geq 15$ years of age. To meet this objective, an estimated HPV prevalence ranging from 10 to $30 \%$ as previously reported $[17,24,25]$, was considered. Given a precision level of 0.045 , the required number of subjects ranged from 188 subjects for a 10\% HPV prevalence to 450 subjects for a $30 \%$ prevalence, including an assumption of $10 \%$ of subjects non-evaluable.

\section{Statistical analyses}

The percentage of women in each category who were HPV positive was tabulated with corresponding 95\% confidence intervals $(\mathrm{CI})$. Descriptive analyses regarding HPV prevalence, HPV-types, age distribution, potential risk factors (education level, life-time marital partners, 
parity and smoking status) and HPV status were performed. An exploratory analysis was performed to assess the association between the HPV status and nationality (two sided Fisher's exact test) and the adjusted odds ratio (adjusted for factors which are associated with the risk of HPV infection) was calculated using multivariate logistic regression model. All statistical analyses were performed using the statistical analysis software $\left(\mathrm{SAS}^{\circ}\right)$ version 9.2.

\section{Ethical considerations}

The study was approved by the following local ethics review bodies: Institutional Review Board at KAMC-NGHA; Institutional Review Board at KFMC; Research Ethics Committee of Office of Research Affairs at KFSH and RC. The study was conducted in accordance with the Declaration of Helsinki, good clinical practice guidelines and local rules and regulations of the country. A written informed consent was obtained from all eligible women before entering the study. The investigator communicated results as appropriate to the subjects, including the need for additional testing or treatment.

\section{Results}

\section{Study population}

Of 420 enrolled women, 417 were included in the final analysis (three were excluded: two due to pregnancy and one due to hysterectomy). A total of 151, 152 and 117 women were enrolled at the KFMC, KFSH and RC, and KAMC-NGHA hospitals, respectively. Overall, 319 women completed the health-related behavior questionnaire and 317 completed the HPV awareness questionnaire. The mean age (standard deviation) of the population was 41.9 $( \pm 10.45)$ years and $77 \%(321 / 417)$ were Saudi nationals. Most women $(93.1 \%, 297 / 319)$ were married and 63.0\% (201/319) had studied up to post-secondary/university level.

\section{Overall HPV prevalence and type distribution}

HPV-DNA was detected in 41 out of 417 women (9.8\%), of whom 25 had single HPV-type infection, 4 had multiple HPV-type infection and at least12 women were infected with non-typeable HPV-types. Overall, the most prevalent HR-HPV-types were HPV-68/73 (5 cases); HPV-18 (4 cases); HPV-16 (3 cases) and the most prevalent LR types were HPV-6 (4 cases); HPV-42, HPV-53 and HPV-54 (2 cases each) (Table 1).

\section{HPV prevalence and type distribution by age}

The prevalence of any HR-HPV was highest (10.9\%) among women over 55 years; LR-HPV-types were also found in $6.5 \%$ of this age group (Figure 1). However, no statistical significance was noted by age group.
Table $1 \mathrm{HPV}$ prevalence and type distribution $(\mathrm{N}=417)$

\begin{tabular}{|c|c|c|c|}
\hline $\mathrm{N}=417$ & $\mathrm{n}$ & $\%$ & $95 \% \mathrm{Cl}$ \\
\hline HPV negative & 376 & 90.2 & $86.9-92.9$ \\
\hline HPV positive & 41 & 9.8 & $7.1-13.1$ \\
\hline Single infection & 25 & 61.0 & $44.5-75.8$ \\
\hline Multiple infection & 4 & 9.8 & $2.7-23.1$ \\
\hline Non-typeable & 12 & 29.3 & $16.1-45.5$ \\
\hline \multicolumn{4}{|l|}{ HPV-types $(n=41)^{*}$} \\
\hline Any high-risk HPV** & 18 & 43.9 & $28.5-60.3$ \\
\hline HPV-68/73 & 5 & 12.2 & $4.1-26.2$ \\
\hline HPV-18 & 4 & 9.8 & $2.7-23.1$ \\
\hline HPV-16 & 3 & 7.3 & $1.5-19.9$ \\
\hline HPV-31 & 2 & 4.9 & $0.6-16.5$ \\
\hline HPV-51 & 2 & 4.9 & $0.6-16.5$ \\
\hline HPV-52 & 2 & 4.9 & $0.6-16.5$ \\
\hline HPV-39 & 1 & 2.4 & $0.1-12.9$ \\
\hline HPV-56 & 1 & 2.4 & $0.1-12.9$ \\
\hline HPV-58 & 1 & 2.4 & $0.1-12.9$ \\
\hline Any low-risk HPV ${ }^{* * *}$ & 14 & 34.1 & $20.1-50.6$ \\
\hline HPV-6 & 4 & 9.8 & $2.7-23.1$ \\
\hline HPV-42 & 2 & 4.9 & $0.6-16.5$ \\
\hline HPV-53 & 2 & 4.9 & $0.6-16.5$ \\
\hline HPV-54 & 2 & 4.9 & $0.6-16.5$ \\
\hline HPV-11 & 1 & 2.4 & $0.1-12.9$ \\
\hline HPV-40 & 1 & 2.4 & $0.1-12.9$ \\
\hline HPV-70 & 1 & 2.4 & $0.1-12.9$ \\
\hline HPV-74 & 1 & 2.4 & $0.1-12.9$ \\
\hline
\end{tabular}

$\mathrm{N}$ : number of women whose cervical samples were tested; $\mathrm{n}$ : number of women in a given category; $95 \% \mathrm{Cl}$ : exact $95 \%$ confidence interval. \#DEIA positive-LiPA negative.

*Some women were infected with multiple HR/LR HPV types.

**Includes 14 women with single HR-HPV infection and 4 women with multiple infections and at least one HR-HPV type.

***Includes 11 women with single LR-HPV infection and 3 women with multiple infections and at least one LR-HPV type.

Note: Single infection $=25 / 417=6.0 \%$ (95\% Cl: 3.9-8.7); Multiple infection $=4$ / $417=0.9 \%(95 \%$ Cl: $0.3-2.4)$; non-typeable $=12 / 417=2.9 \%(95 \%$ Cl: $1.5-5.0)$.

\section{HPV prevalence and type distribution by nationality}

The prevalence of HPV was higher $(16.7 \%$ vs. $7.8 \%, P=$ 0.0234) among non-Saudi nationals $(\mathrm{n}=96)$ as compared with Saudi nationals $(\mathrm{n}=321)$ respectively (Figure 2$)$.

\section{HPV co-infection}

Multiple infections were observed in four women; three of whom were infected with HR-HPV-68/73 (-68/73 with $-52,-39,-53 ;-68 / 73$ with -40 ; and $-68 / 73$ with -54$)$. One woman had a co-infection of HR-HPV-16 with -31 . No HR-HPV-18 positive women were co-infected with any other HR-HPV-types. 


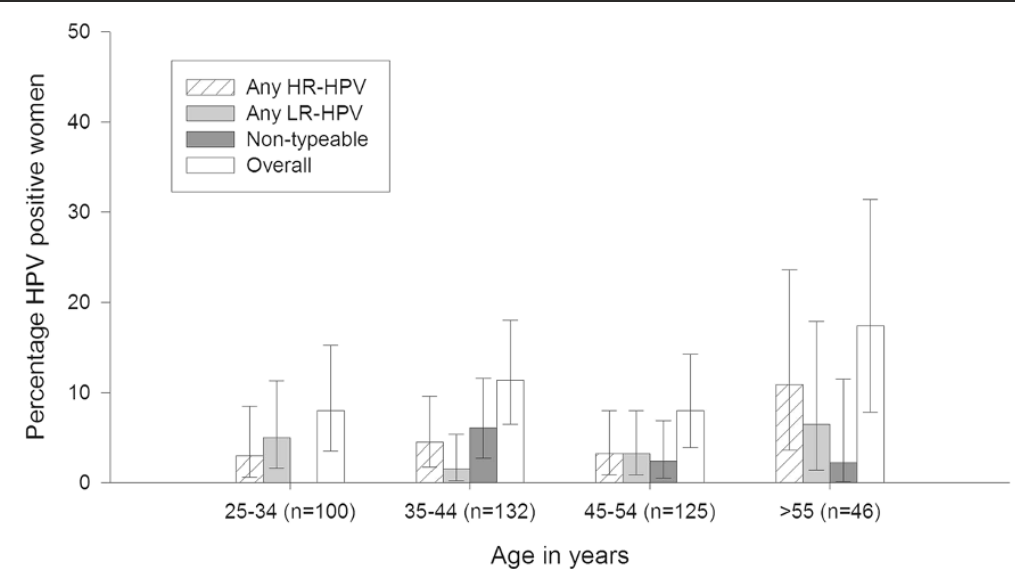

Figure 1 HPV prevalence and type distribution by age $\left(\mathrm{N}=417^{*}\right)$. Note: For 2 women, dates were not available; hence age could not be estimated. Note: The error bars represent $95 \%$ confidence intervals.

\section{Awareness and health related behavior questionnaire results}

The potential risk factors of educational level, number of life-time partners, parity and smoking status assessed using univariate analyses showed no statistical associations with any HPV infection (Table 2). Of 317 women completing the HPV awareness questionnaire, 101 (32.2\%) were aware of HPV and 285 (89.9\%) expressed an interest in vaccination (Table 3 ).

\section{Discussion}

This study estimated the prevalence and type distribution of HPV in 417 women above 15 years of age attending routine gynecological screening at three large hospitals in Riyadh, Saudi Arabia. We reported a 9.8\% prevalence for $\mathrm{HPV}$, which is much lower than the $31.6 \%$ overall prevalence of HPV-16/18 reported previously in a small study involving subjects from Riyadh [24]. An earlier report from Jeddah reported a 5.6\% prevalence of HR-types [17]. These differences could be due to many factors including differences in HPV testing technology, study size, age groups or geographical variations. The study which was undertaken in Riyadh [24] included a limited number of subjects (75 Saudi nationals and 45 from other countries) from just one hospital (which was also included in our study). The higher proportion of non-Saudi nationals in this study might help to explain the observed higher HPV prevalence [24]. Conversely, although the sample size in the study conducted in Jeddah [17] was similar to that in our present study, the exclusion of non-Saudi nationals might explain the lower reported HPV prevalence. According to available data, our study included a

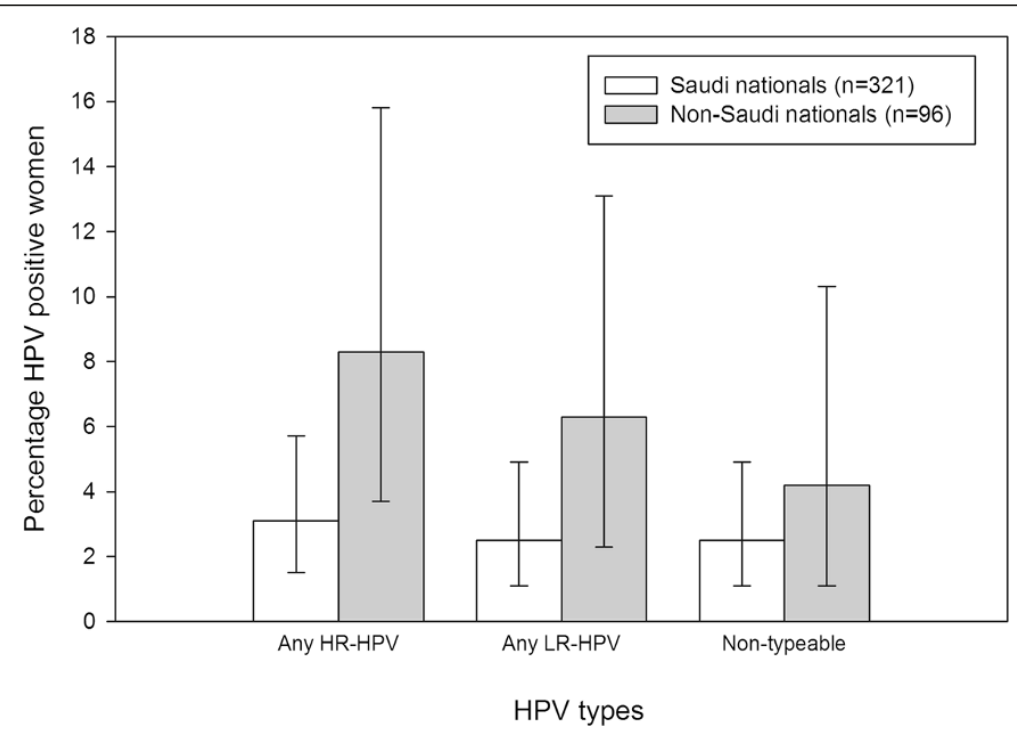

Figure 2 HPV prevalence and type distribution by nationality $(\mathbf{N}=\mathbf{4 1 7})$. Note: The error bars represent $95 \%$ confidence intervals. 
Table 2 Prevalence of any HPV by risk factors $(\mathrm{N}=319)$

\begin{tabular}{|c|c|c|c|c|c|c|c|}
\hline Risk factors & Categories & $\mathbf{N}$ & $\mathrm{HPV}+$ & $\%$ & Adj. OR & LL-UL & $P$ value \\
\hline \multirow[t]{5}{*}{ Age at sample collection (years) } & $<30^{*}$ & 56 & 3 & 5.36 & . & . & . \\
\hline & $30-39$ & 124 & 12 & 9.68 & 3.310 & $0.391-28.052$ & 0.2723 \\
\hline & $40-49$ & 132 & 12 & 9.09 & 2.097 & $0.230-19.085$ & 0.5110 \\
\hline & $50-60$ & 89 & 12 & 13.48 & 4.136 & $0.454-37.681$ & 0.2079 \\
\hline & $>60$ & 14 & 2 & 14.29 & 9.570 & $0.601-152.366$ & 0.1097 \\
\hline \multirow[t]{2}{*}{ Nationality } & Non-Saudi* & 96 & 16 & 16.67 & . & & . \\
\hline & Saudi & 321 & 25 & 7.79 & 0.315 & $0.116-0.855$ & 0.0234 \\
\hline \multirow[t]{4}{*}{ Education level } & No formal education* & 21 & 2 & 9.52 & . & & . \\
\hline & Primary & 47 & 3 & 6.38 & 1.039 & $0.144-7.489$ & 0.9693 \\
\hline & Secondary & 50 & 4 & 8.00 & 1.515 & $0.200-11.492$ & 0.6879 \\
\hline & Post-secondary/University & 201 & 24 & 11.94 & 1.158 & $0.180-7.447$ & 0.8770 \\
\hline \multirow[t]{2}{*}{ Number of marital partners } & $1^{*}$ & 286 & 29 & 10.14 & . & . & . \\
\hline & $2-5$ & 32 & 4 & 12.50 & 1.129 & $0.324-3.941$ & 0.8488 \\
\hline \multirow[t]{4}{*}{ Parity } & $0^{*}$ & 8 & 0 & 0.00 & & . & . \\
\hline & $1-2$ & 100 & 11 & 11.00 & >999.999 & $<0.001->999.999$ & 0.9516 \\
\hline & $3-5$ & 112 & 14 & 12.50 & $>999.999$ & $<0.001->999.999$ & 0.9502 \\
\hline & $\geq 6$ & 71 & 5 & 7.04 & $>999.999$ & $<0.001->999.999$ & 0.9518 \\
\hline \multirow[t]{2}{*}{ Smoking status } & $\mathrm{No}^{*}$ & 273 & 30 & 10.99 & & . & . \\
\hline & Yes & 44 & 3 & 6.82 & 0.502 & $0.134-1.875$ & 0.3053 \\
\hline
\end{tabular}

$\mathrm{N}$ : number of subjects in a given cohort; \%: HPV+/number of subjects with available results $\times 100 ;$ Adj. OR: Adjusted odds ration from simple logistic regression model Odds ratio adjusted for the other variables; $95 \% \mathrm{Cl}$ : Wald 95\% confidence interval; LL: lower limit; UL: upper limit.

*Reference category.

representative number of Saudi and non-Saudi nationals, which reflects the current demography of Saudi Arabia [25]. This might explain higher HPV prevalence in our study compared to the Jeddah study. Our study might therefore be more representative of the current situation in Saudi Arabia given the larger sample size as well as the inclusion of non-Saudi nationals.

Indeed, data from the Saudi Cancer registry suggest that there are regional differences in the percentage distribution of $\mathrm{CC}$ with the northern region having the highest $(6.4 \%)$ percentage distribution compared with the other regions [26].

According to the United Nations classification, Saudi Arabia belongs to the Western Asia region [27], which has a lower HPV prevalence rate $(2.2 \%$ [95\% CI, 1.53.1]) compared with global rates (11.4\% [95\% CI, 11.311.5]) in women with normal cytology [2]. The crude incidence rate of CC per 100,000 women per year in Saudi Arabia is 1.3, which is lower than that in Western Asia (3.6) and the world (15.8) [2]. The prevalence of HPV in women with CC in Saudi Arabia has a broad range $(43-89 \%)$ [28,29] compared with the global prevalence (85-99\%) [6]. The low rates of CC in Saudi Arabia as compared with other countries could be due to differences in sexual practices and attitudes. For example, the population in Saudi Arabia is more conservative than western countries where most of the data derive [30]. The exact reasons for these low rates in Saudi Arabia are not known, but highlight the need for recent data to better understand the disease burden of HPV and the prevalent circulating types.

The most prevalent HR-HPV-types reported in our study were HPV-68/73, 18 and 16; the most common LR-HPV-types were HPV-6, 42, 53 and 54. HPV-types 16 and 18 have been predominantly reported in HPV infections globally and the results of our study were therefore consistent [24,31]. We did however note a high prevalence of HPV-68/73 for the first time, especially among non-Saudi nationals. HPV-68 type has been reported throughout the world, with the exception of North America, albeit at a lower prevalence [32]. However, our results should be considered with caution as only five women were positive for HPV-68/73. Future studies to substantiate this finding are therefore indicated.

Our study also found that HR-HPV infection was highest $(10.9 \%)$ in the oldest age group ( $>55$ years). These results are consistent with the general worldwide trend of higher HPV burden in older women. However, the comparator study from Bruni et al. [31] only included women with normal cytology whereas the cytology status was not known in the present study [32]. 
Table 3 Awareness of HPV infection among women ( $\mathrm{N}=317)$

Characteristics
How common is cervical cancer
in women?
What do you think is/are the
main reasons for cervical cancer?
Which among these can
pregnancy, what would you
think can happen with using
contraceptive pills*
What do you think can turn
in to cervical cancer*

\begin{tabular}{|c|c|c|c|}
\hline & No ill effect at all & 77 & 24.3 \\
\hline & Not sure & 86 & 27.1 \\
\hline \multirow[t]{3}{*}{ Did you hear about HPV before? } & Yes & 101 & 32.2 \\
\hline & No & 213 & 67.8 \\
\hline & Missing & 3 & - \\
\hline \multirow[t]{5}{*}{ If yes*, } & General physician & 28 & 8.8 \\
\hline & Friend or family member & 20 & 6.3 \\
\hline & Internet & 22 & 6.9 \\
\hline & TV/Magazine/Newspaper & 46 & 14.5 \\
\hline & Other & 14 & 4.4 \\
\hline \multirow[t]{5}{*}{ How is HPV transmitted?* } & $\begin{array}{l}\text { Contaminated } \\
\text { food/Water }\end{array}$ & 10 & 3.2 \\
\hline & Mosquito bite & 3 & 0.9 \\
\hline & Sexually & 159 & 50.2 \\
\hline & None & 20 & 6.3 \\
\hline & Not sure & 127 & 40.1 \\
\hline \multirow{3}{*}{$\begin{array}{l}\text { How is cervical cancer } \\
\text { diagnosed?* }\end{array}$} & Pap smear test & 77 & 24.3 \\
\hline & Colposcopy & 24 & 7.6 \\
\hline & $\begin{array}{l}\text { Biopsy sample testing } \\
\text { (histological) }\end{array}$ & 122 & 38.5 \\
\hline
\end{tabular}

\begin{tabular}{lll} 
Categories & $\mathbf{n}$ & $\%$ \\
\hline Very common & 48 & 15.1
\end{tabular}

$\begin{array}{lcc}\text { Common } & 157 & 49.5 \\ \text { Rare } & 56 & 17.7\end{array}$

Not sure $\quad 56 \quad 17.7$

It develops from inside $\quad 95 \quad 30.0$

Bacterial infection $\quad 49 \quad 15.5$

Viral infection $\quad 80 \quad 25.2$

None $\quad 14 \quad 4.4$

Not sure $\quad 85 \quad 26.8$

Persistent infection $\quad 82 \quad 25.9$

with HPV

Rous sarcoma virus $\quad 23 \quad 7.3$

Hereditary/genetic factors $115 \quad 36.3$

None $\quad 18 \quad 5.7$

Not sure

Genital warts

$88 \quad 27.8$

Bacterial infection

$109 \quad 34.4$

Fungal infection

None

Not sure

Protects against cervical cancer

Increases risk of cervical cancer

No ill effect at all

$\begin{array}{ll}56 & 17.7\end{array}$

$\begin{array}{ll}26 & 8.2\end{array}$

$23 \quad 7.3$

$108 \quad 34.1$

$31 \quad 9.8$

$123 \quad 38.8$

$77 \quad 24.3$

$86 \quad 27.1$

32.2

367.8

8.8

6.3

6.9

14.5

4.4

in

Table 3 Awareness of HPV infection among women ( $\mathbf{N}=\mathbf{3 1 7}$ ) (Continued)

\begin{tabular}{llll}
\hline & All above & 82 & 25.9 \\
& None & 2 & 0.6 \\
& Not sure & 30 & 9.5 \\
Is it possible to prevent cancer? & Yes & 243 & 78.9 \\
& No & 26 & 8.4 \\
& Not sure & 39 & 12.7 \\
& Missing & 9 & - \\
& Through cancer vaccine & 58 & 18.3 \\
& Through responsible & 46 & 14.5 \\
If yes*, & sexual behavior & & \\
& Through cervical & 173 & 54.6 \\
& screening & & \\
& Through condom use & 14 & 4.4 \\
& Yes & 285 & 89.9 \\
If the vaccine against cervical \\
$\begin{array}{ll}\text { cancer is available, would you be } \\
\text { interested in getting vaccinated? }\end{array}$ & No & 32 & 10.1 \\
\hline
\end{tabular}

$\mathrm{N}$ : number of women in a specified category for whom questionnaire data were collected.

*Women could have selected more than one option.

We estimated a higher proportion of infection in nonSaudi nationals compared with the Saudi nationals. This difference could be due to many reasons including different cultural behaviors such as male circumcision [32,33], sexual behavior or prevalence in the native countries. Further studies are therefore warranted. Although, it appears that non-Saudi nationals are at a greater risk of contracting infection, prevalent HPV types indeed pose a risk of infecting Saudi nationals. Our study did not find educational level, number of lifetime partners, parity or smoking status to be significantly associated risk factors for HPV-16, HPV-18 or any HR-HPV infection.

Our study results should be interpreted with caution as the study design was cross sectional, i.e., we obtained single point estimates of women with HPV infections. These infections could have been transient and resolved on their own rather than leading to CC. In addition, since the overall number of women positive for HPV itself was low, the prevalence of HPV types should be interpreted with caution. Another limitation lies within the recruitment process: women with higher levels of education are more likely to opt for cervical cancer screening and therefore would be more likely to participate in our study. Nevertheless, our study did also include women who did not have formal education.

A major strength of this study was the high quality of HPV-DNA testing across the three hospitals in all age groups which helps to provide a representative sample of the population. The study also met the required sample size to calculate an overall prevalence of $9.8 \%$ with 
good precision. Furthermore, the questionnaires were completed by most enrolled women giving an important insight into behavior and attitudes, and suggesting that the introduction of a preventive measure such as vaccination would be accepted. Reports indicate that the proportion of non-Saudi nationals represent $20 \%-30 \%$ of the entire population in Saudi Arabia [25,34] which is consistent with our results (23\%). In addition, the proportion of women completing up to post-secondary/university level education in our study (63\%) is comparable to the Organization for Economic Co-operation and Development (OECD) reports, where at least $50 \%$ of women were educated and at least 54\% of women among all OECD countries completed post-secondary education [35]. These comparisons therefore indicate the representativeness of our study population.

The study results emphasize the need for a future updated policy for HPV and CC prevention in Saudi Arabia. A World Health Organization document on cancer control in the Eastern Mediterranean region describes that only $35 \%$ of CC cases present at early stage; as in other developing countries, the rest are reported at later stages when cure is unlikely, even with the best treatment [34]. It has also been reported that when women are double negative in the conventional cytological screening test and the highly sensitive HPV molecular test, then screening can be performed at longer intervals [36]. Our study findings together with these data will help determine the best strategy for targeting preventive interventions, and designing public health measures for Saudi Arabia.

\section{Conclusion}

The overall results from this study emphasize that the HPV burden in Saudi Arabia is a cause for concern and preventive strategies such as screening, HPV-DNA testing of cervical samples and vaccination might reduce the burden of the disease. Our data can raise the awareness of local authorities and public health officials and help to guide policy in Saudi Arabia to implement strategies to prevent CC.

\section{Trademark}

Cervarix is a trademark of the GlaxoSmithKline group of companies

Gardasil is a trademark of Merck \& Co. Inc.

PreservCyt is a trademark of Cytyc Corporation, Massachusetts, United States of America

Labo Biomedical Products, Rijswijk, The Netherlands

\footnotetext{
Abbreviations

CC: Cervical cancer; Cl: Confidence interval; DEIA: DNA enzyme immunoassay; HPV: Human papillomavirus; HR: High-risk; KAMC-NGHA: King Abdulaziz Medical City-National Guard Health Affairs; KFMC: King Fahd Medical City; KFSH and RC: King Faisal Specialist Hospital and Research Centre; LiPA25: Line probe assay 25; LR: Low-risk; OECD: Organization for Economic Co-operation and Development; PCR: Polymerase chain reaction; SAS: Statistical analysis software; SPF-10: Short PCR fragment 10.
}

\section{Competing interests}

MAA and his institution received a grant from GlaxoSmithKline group of companies to cover costs of samples collection and initial processing; IAB and HAK and their respective institutions received financial assistance from GlaxoSmithKline group of companies for study conduct; RD, WK and KG are employed by the GlaxoSmithKline group of companies and RD has stock options; AAO and WQ have no conflict of interest to declare.

\section{Authors' contributions}

$A A O, I A B$ and HAK were the coordinating investigators and in collaboration with MAA were responsible for the conduct of the study at the three sites, $A A O, I A B, H A K, M A A$ and WK were involved in the design of the study, analysis and interpretation of the results. KG contributed to the study design and performed the statistical analysis. WQ was responsible for HPV genotyping, and contributed to the analysis of the results. RD managed the study at GlaxoSmithKline Vaccines and contributed to the analysis, interpretation and critically reviewed the study report. All authors had access to the data and participated in the drafting, review and approval of the manuscript. The corresponding author took final responsibility for submitting the manuscript.

\section{Acknowledgements}

The authors would like to thank Dr. Mamoun ElAwad for his participation in the conduct of the study, Karin Hallez and Mohammed Bassyouni for monitoring the study sites (both employed by GlaxoSmithKline group of companies). The authors also thank Shruti Priya Bapna, Harshith Bhat and Preethi Govindarajan (all employed by GlaxoSmithKline group of companies) for preparation of the manuscript, Julia Donnelly (on behalf of GlaxoSmithKline Vaccines) for language editing and Abdelilah Ibrahimi (XPE Pharma and Science on behalf of GlaxoSmithKline Vaccines) for publication coordination.

\section{Funding source}

GlaxoSmithKline Biologicals SA sponsored and funded the study conduct, analyses of data and the development and publication of the manuscript.

\section{Author details}

${ }^{1}$ King Fahd Medical City, P.O. Box 59046, Riyadh 11525, Saudi Arabia. ${ }^{2}$ King Faisal Specialist Hospital \& Research Centre, P.O. Box 3354, Riyadh 11211 , MBC-52, Saudi Arabia. ${ }^{3}$ Department of Obstetrics and Gynecology, King Abdulaziz Medical City, College of Medicine, King Saud bin Abdulaziz University for Health Sciences, P.O Box 22490, Riyadh 11426, Saudi Arabia. ${ }^{4}$ GlaxoSmithKline Pharmaceuticals Ltd, Bangalore, India. ${ }^{5} \mathrm{GlaxoSmithKline}$ Vaccines, Wavre, Belgium. ${ }^{6}$ DDL Diagnostic Laboratory, Rijswijk, the

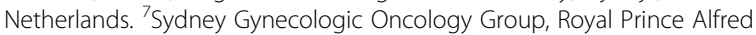
Hospital, Sydney, Australia.

Received: 22 April 2014 Accepted: 19 November 2014

Published online: 14 December 2014

\section{References}

1. Ferlay J, Shin HR, Bray F, Forman D, Mathers C, Parkin DM: Estimates of worldwide burden of cancer in 2008: GLOBOCAN 2008. Int J Cancer 2010, 127(12):2893-2917.

2. Rana MM, Huhtala H, Apter D, Eriksson T, Luostarinen T, Natunen $K$, Paavonen J, Pukkala E, Lehtinen M: Understanding long-term protection of human papillomavirus vaccination against cervical carcinoma: Cancer registry-based follow-up. Int J Cancer 2013, 132(12):2833-2838.

3. WHO/ICO Information Centre on HPV and CC Human Papillomavirus and Related Cancers in Saudi Arabia. [http://www.who.int/immunization/ topics/hpv/en/]. Last accessed: 06 Jan 2014.

4. Walboomers JM, Jacobs MV, Manos MM, Bosch FX, Kummer JA, Shah KV, Snijders PJ, Peto J, Meijer CJ, Munoz N: Human papillomavirus is a necessary cause of invasive cervical cancer worldwide. J Pathol 1999, 189(1):12-19.

5. Munoz N, Bosch FX, de Sanjose S, Herrero R, Castellsague X, Shah KV, Snijders PJ, Meijer CJ, International Agency for Research on Cancer Multicenter Cervical Cancer Study G: Epidemiologic classification of human papillomavirus types associated with cervical cancer. N Engl J Med 2003, 348(6):518-527.

6. de Sanjose S, Quint WG, Alemany L, Geraets DT, Klaustermeier JE, Lloveras B, Tous S, Felix A, Bravo LE, Shin HR, Vallejos CS, de Ruiz PA, Lima MA, Guimera 
N, Clavero O, Alejo M, Llombart-Bosch A, Cheng-Yang C, Tatti SA, Kasamatsu E, Iljazovic E, Odida M, Prado R, Seoud M, Grce M, Usubutun A, Jain A, Suarez GA, Lombardi LE, Banjo A, et al: Human papillomavirus genotype attribution in invasive cervical cancer: a retrospective cross-sectional worldwide study. Lancet Oncol 2010, 11(11):1048-1056.

7. Descamps D, Hardt K, Spiessens B, Izurieta P, Verstraeten T, Breuer T, Dubin G: Safety of human papillomavirus (HPV)-16/18 AS04-adjuvanted vaccine for cervical cancer prevention: a pooled analysis of 11 clinical trials. Hum Vaccin 2009, 5(5):332-340.

8. Paavonen J, Naud P, Salmeron J, Wheeler CM, Chow SN, Apter D, Kitchener $H$, Castellsague X, Teixeira JC, Skinner SR, Hedrick J, Jaisamrarn U, Limson G, Garland S, Szarewski A, Romanowski B, Aoki FY, Schwarz TF, Poppe WA, Bosch FX, Jenkins D, Hardt K, Zahaf T, Descamps D, Struyf F, Lehtinen M, Dubin G, Group HPS: Efficacy of human papillomavirus (HPV)-16/18 AS04adjuvanted vaccine against cervical infection and precancer caused by oncogenic HPV types (PATRICIA): final analysis of a double-blind, randomised study in young women. Lancet 2009, 374(9686):301-314.

9. Einstein MH, Baron M, Levin MJ, Chatterjee A, Fox B, Scholar S, Rosen J, Chakhtoura N, Meric D, Dessy FJ, Datta SK, Descamps D, Dubin G, Group HPVS: Comparative immunogenicity and safety of human papillomavirus (HPV)-16/18 vaccine and HPV-6/11/16/18 vaccine: follow-up from months 12-24 in a Phase III randomized study of healthy women aged 18-45 years. Hum Vaccin 2011, 7(12):1343-1358.

10. Verstraeten T, Descamps D, David MP, Zahaf T, Hardt K, Izurieta P, Dubin G, Breuer T: Analysis of adverse events of potential autoimmune aetiology in a large integrated safety database of ASO4 adjuvanted vaccines. Vaccine 2008, 26(51):6630-6638.

11. Castellsague $X$, Munoz N, Pitisuttithum P, Ferris D, Monsonego J, Ault K, Luna J, Myers E, Mallary S, Bautista OM, Bryan J, Vuocolo S, Haupt RM, Saah A: End-of-study safety, immunogenicity, and efficacy of quadrivalent HPV (types $6,11,16,18$ ) recombinant vaccine in adult women 24-45 years of age. Br J Cancer 2011, 105(1):28-37.

12. Lehtinen M, Paavonen J, Wheeler CM, Jaisamrarn U, Garland SM, Castellsague X, Skinner SR, Apter D, Naud P, Salmeron J, Chow SN, Kitchener H, Teixeira JC, Hedrick J, Limson G, Szarewski A, Romanowski B, Aoki FY, Schwarz TF, Poppe WA, De Carvalho NS, Germar MJ, Peters K, Mindel A, De Sutter P, Bosch FX, David MP, Descamps D, Struyf F, Dubin G, et al: Overall efficacy of HPV-16/18 AS04-adjuvanted vaccine against grade 3 or greater cervical intraepithelial neoplasia: 4-year end-of-study analysis of the randomised, double-blind PATRICIA trial. Lancet Oncol 2012, 13(1):89-99.

13. Roteli-Martins CM, Naud P, De Borba P, Teixeira JC, De Carvalho NS, Zahaf T, Sanchez N, Geeraerts B, Descamps D: Sustained immunogenicity and efficacy of the HPV-16/18 AS04-adjuvanted vaccine: up to 8.4 years of follow-up. Hum Vaccin Immunother 2012, 8(3):390-397.

14. Wheeler CM, Castellsague X, Garland SM, Szarewski A, Paavonen J, Naud P, Salmeron J, Chow SN, Apter D, Kitchener H, Teixeira JC, Skinner SR, Jaisamrarn U, Limson G, Romanowski B, Aoki FY, Schwarz TF, Poppe WA, Bosch FX, Harper DM, Huh W, Hardt K, Zahaf T, Descamps D, Struyf F, Dubin G, Lehtinen M, Group HPS: Cross-protective efficacy of HPV-16/18 AS04-adjuvanted vaccine against cervical infection and precancer caused by non-vaccine oncogenic HPV types: 4-year end-of-study analysis of the randomised, double-blind PATRICIA trial. Lancet Oncol 2012, 13(1):100-110.

15. Al-Badawi IA, Al-Suwaine A, Al-Aker M, Asaad L, Alaidan A, Tulbah A, Fe Bohol M, Munkarah AR: Detection and genotyping of human papilloma virus in cervical cancer specimens from Saudi patients. Int J Gynecol Cancer 2011, 21(5):907-910.

16. Alsbeih G, Ahmed R, Al-Harbi N, Venturina LA, Tulbah A, Balaraj K: Prevalence and genotypes' distribution of human papillomavirus in invasive cervical cancer in Saudi Arabia. Gynecol Oncol 2011, 121(3):522-526.

17. Bondagji NS, Gazzaz FS, Sait K, Abdullah L: Prevalence of high-risk human papillomavirus infections in healthy Saudi women attending gynecologic clinics in the western region of Saudi Arabia. Ann Saudi Med 2013, 33(1):13-17.

18. Sait $\mathrm{KH}$ : Attitudes, knowledge, and practices in relation to cervical cancer and its screening among women in Saudi Arabia. Saudi Med J 2009, 30(9):1208-1212.

19. Sait KH: Knowledge, attitudes, and practices regarding cervical cancer screening among physicians in the Western Region of Saudi Arabia. Saudi Med J 2011, 32(11):1155-1160.

20. Geraets DT, van Baars R, Alonso I, Ordi J, Torne A, Melchers WJ, Meijer CJ, Quint WG: Clinical evaluation of high-risk HPV detection on self-samples using the indicating FTA-elute solid-carrier cartridge. J Clin Virol 2013, 57(2):125-129.

21. van Doorn LJ, Molijn A, Kleter B, Quint W, Colau B: Highly effective detection of human papillomavirus 16 and 18 DNA by a testing algorithm combining broad-spectrum and type-specific PCR. J Clin Microbiol 2006, 44(9):3292-3298.

22. Kleter B, van Doorn LJ, Schrauwen L, Molijn A, Sastrowijoto S, ter Schegget J, Lindeman J, ter Harmsel B, Burger M, Quint W: Development and clinical evaluation of a highly sensitive PCR-reverse hybridization line probe assay for detection and identification of anogenital human papillomavirus. J Clin Microbiol 1999, 37(8):2508-2517

23. de Sanjose S, Diaz M, Castellsague X, Clifford G, Bruni L, Munoz N, Bosch FX: Worldwide prevalence and genotype distribution of cervical human papillomavirus DNA in women with normal cytology: a meta-analysis. Lancet Infect Dis 2007, 7(7):453-459.

24. Al-Muammar T, Al-Ahdal MN, Hassan A, Kessie G, Dela Cruz DM, Mohamed GE: Human papilloma virus-16/18 cervical infection among women attending a family medical clinic in Riyadh. Ann Saudi Med 2007, 27(1):1-5.

25. Central Intelligence Agency: The World factbook: Middle East: Saudi Arabia. [https://www.cia.gov/library/publications/the-world-factbook/geos/ sa.html]. Last accessed: 06 Jan 2014.

26. Cancer Incidence Report Saudi Arabia 2004. National Cancer Registry, Ministry of Health. [http://www.kfshrc.edu.sa/wps/wcm/connect/40dcba 804a8d741fb731f7e404c39865/SCR2004W.pdf?MOD=AJPERES\&lmod=1265 914960\&CACHEID=40dcba804a8d741fb731f7e404c39865]. Last accessed: 06 Jan 2014

27. United Nations Statistics Division: Standard country and area codes classifications (M49). [http://unstats.un.org/unsd/methods/m49/m49regin.htm]. Last accessed: 06 Jan 2014.

28. Turki R, Sait K, Anfinan N, Sohrab SS, Abuzenadah AM: Prevalence of human papillomavirus in women from Saudi Arabia. Asian Pac J Cancer Prev 2013, 14(5):3177-3181.

29. Alsbeih G, Al-Harbi N, El-Sebaie M, Al-Badawi I: HPV prevalence and genetic predisposition to cervical cancer in Saudi Arabia. Infect Agent Cancer 2013, 8(1):15.

30. Mackay J: Global sex: sexuality and sexual practices around the world. Sex Relation Ther 2001, 16(1):71-82.

31. Bruni L, Diaz M, Castellsague X, Ferrer E, Bosch FX, de Sanjose S: Cervical human papillomavirus prevalence in 5 continents: meta-analysis of 1 million women with normal cytological findings. J Infect Dis 2010, 202(12):1789-1799.

32. Davis MA, Gray RH, Grabowski MK, Serwadda D, Kigozi G, Gravitt PE, Nalugoda F, Watya S, Wawer MJ, Quinn TC, Tobian AA: Male circumcision decreases high-risk human papillomavirus viral load in female partners: A randomized trial in Rakai. Uganda Int J Cancer 2013, 133(5):1247-1252.

33. Morris BJ, Mindel A, Tobian AA, Hankins CA, Gray RH, Bailey RC, Bosch X, Wodak AD: Should male circumcision be advocated for genital cancer prevention? Asian Pac J Cancer Prev 2012, 13(9):4839-4842. Demographics of Saudi Arabia [http://www.princeton.edu/ achaney/tmve/wiki100k/docs/ Demographics_of_Saudi_Arabia.html]. Last accessed: 06 Jan 2014.

34. Towards a Stratergy for Cancer Control in the Eastern Mediterranean Region. [http://applications.emro.who.int/dsaf/dsa1002.pdf]. Last accessed: 06 Jan 2014.

35. Education at a Glance 2012. [http://www.oecd.org/edu/highlights.pdf]. Last accessed: 06 Jan 2014.

36. Gazzaz FB: Molecular testing of human papillomavirus in cervical specimens. Saudi Med J 2007, 28(12):1810-1818.

doi:10.1186/s12879-014-0643-8

Cite this article as: AlObaid et al:: Human papillomavirus prevalence and type distribution among women attending routine gynecological examinations in Saudi Arabia. BMC Infectious Diseases 2014 14:643. 